\title{
An unusual complication and imaging of PTFE membrane: Report of a case
}

Tuğba Avcl, Irfan Taşoğlu, Emre Aygün and Mustafa Paç Yüksek İhtisas Eğitim ve Araşı̧ırma Hastanesi, Ankara, Turkey Department of Cardiovascular Surgery, Turkey

\section{Article Info}

\section{Article Notes}

Received: July 22, 2016

Accepted: November 02, 2016

\section{*Correspondence:}

Tuğba Avcı M.D., Department of Cardiovascular Surgery, High Education and Research Hospital of Turkey.

Türkiye Yüksek Ihtisas Hastanesi Kalp ve Damar Cerrahisi Sekreterliği 2. Kat Kızılay sok. Altındağ / Ankara, Fax: +90 (312) 22901 48; Tel: +90 (505) 4402428

E-mail: dr.tugbadonmez@gmail.com

(c) 2016 Tuğba Avcl. This article is distributed under the terms of the Creative Commons Attribution 4.0 International License.

\section{Keywords:}

Cardiac surgery

Polytetrafluoroethylene (PTFE)

Pericardial closure

Prosthetic materials

Complications

\section{ABSTRACT}

Background: There are many usage areas of the PTFE patch in cardiac surgery. In this report, we present an unusual complication which should be kept in mind about PTFE membranes.

Case presentation: The 20-year-old male patient had been operated for ascending aortic aneurysm. David Procedure was carried out. After (in)the procedure, before the sternal closure, the pericardial closure was applied with PTFE membrane to avoid the sternal adhesions. The sternal wound drainage occurred two months after the operation. After further evaluations, surgery was the choice. The cure was achieved by removing the PTFE membrane. The sternum closure was applied without pericardial closure. His wound healed fastly.

Conclusions: The complications about prosthetic materials are trouble for surgeons. In many cases, the cure is achieved by removing the prosthetic materials. In most times, radiology is helpful for diagnosis, but rarely, it might be a misleading procedure.

\section{Introduction}

Many surgeons experience many retained surgical material events with a risk of patient morbidity, and also medicolegal problems. Identification of these materials is highly challenging and important. The radiologists should be attentive to imaging finding of retained surgical materials. There is a widespread usage of PTFE patch in cardiac surgery such as in ventricular septal defect (VSD) closure or in prevention of postoperative adhesions ${ }^{1}$. In this report, we present an unusual complication about PTFE membranes.

\section{Presentation of the Case}

20-year-old male patient: He had been operated for a ventricular septal defect at the age of 4 years. He was referred to the pediatric cardiologist because of ascending aortic aneurysm. Valve-sparing aortic root replacement (David Procedure) was carried out with the dacron graft. After the bleeding control and drainage tube insertion, aorta and heart were coated by using $0,6 \mathrm{~mm}$ PTFE membrane in order to avoid adhesions. The layer was stitched with 4.0 polypropylene suture continuously untill the edge of the native pericardium. There has been no complication related to surgery. After his discharge, on the 40th postoperative day of his surgery, sternal wound drainage occurred on the incisura jugularis region. His sternum was intact. Wound cultures were negative, and there was no evidence that shows an infection. He had a low-grade 
fever. Also, CRP and sedimentation levels were high, but procalcitonin levels were normal. White blood cell count was normal. Monocytes were higher in value. Thorax CT was performed to the patient to see if there was a problem. According to the report of the radiologist, the opacity on the anterior mediastinum belonged to surgical gauze which was forgotten inside during previous surgery (Figure 1). X-Ray images did not confirm this opinion (Figure 2), but both CT images and patient's clinical condition forced us to opt for reoperation for exploration of the mediastinum.

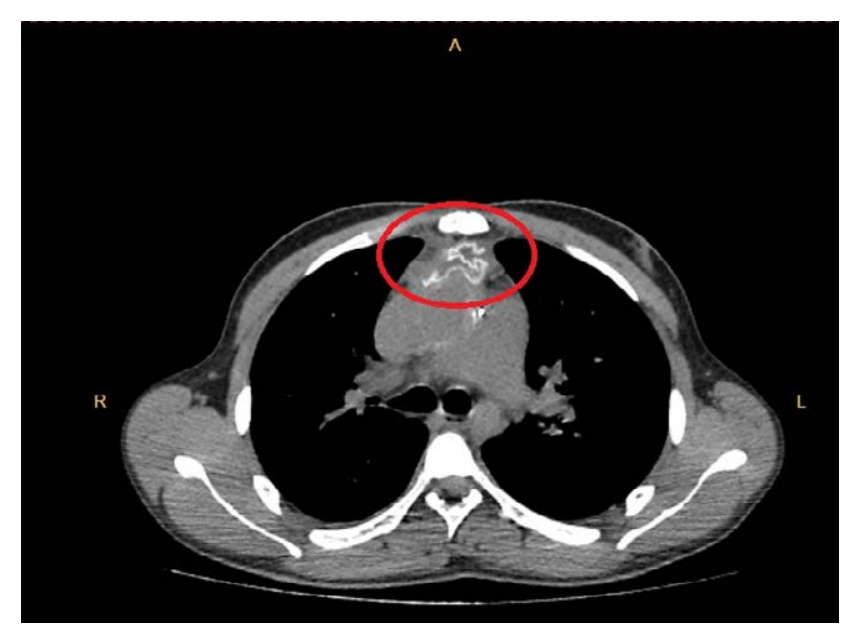

Figure 1:

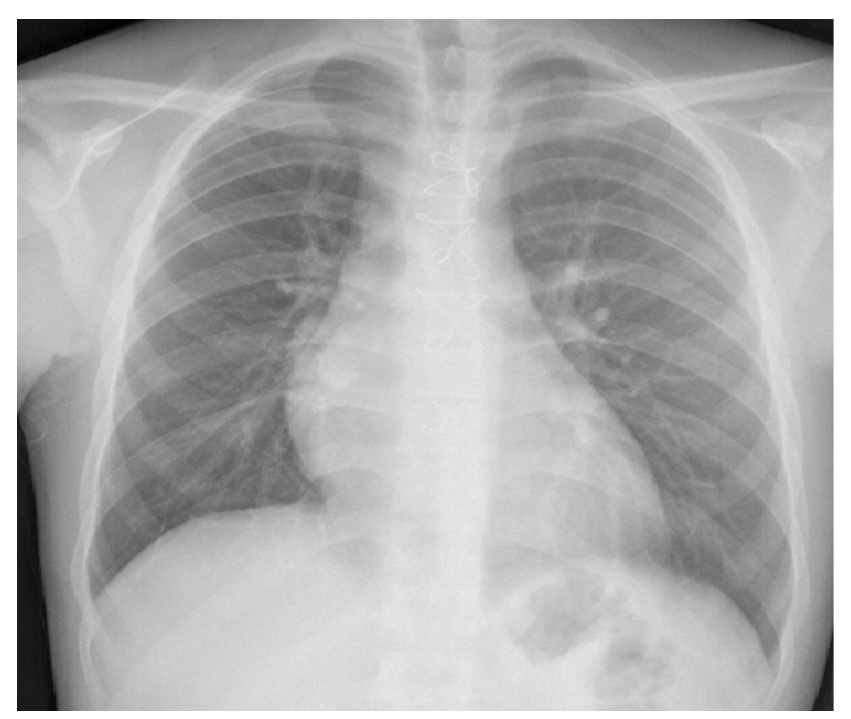

Figure 2:

\section{Results}

We decided to re-operate the patient based on these results. After standard preoperative procedures, sternum was opened with the striker, carefully. There was not any surgical gauze in there, but the $0,6 \mathrm{~mm}$ PTFE membrane was laying on the heart (Figure3). The sutures were almost

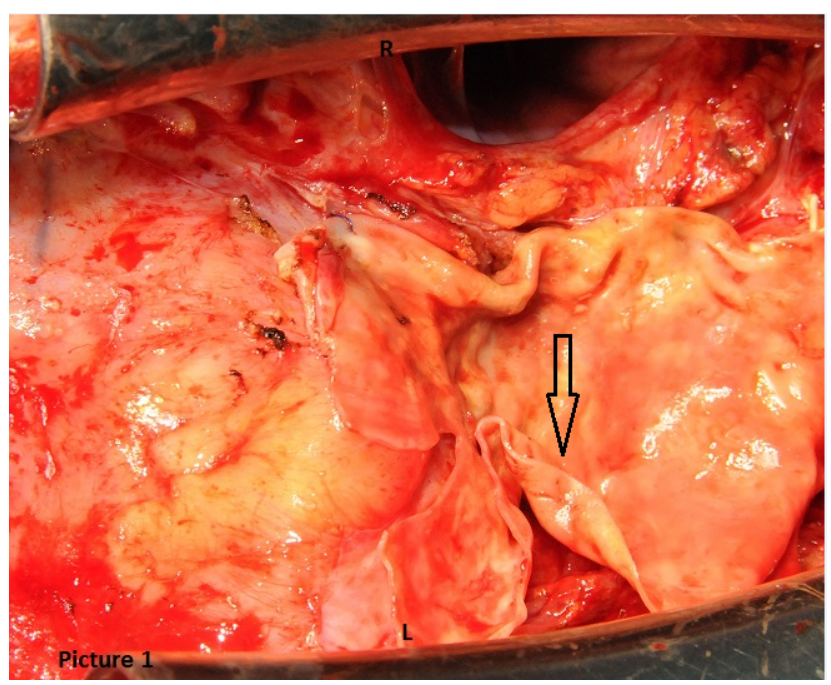

Figure 3:

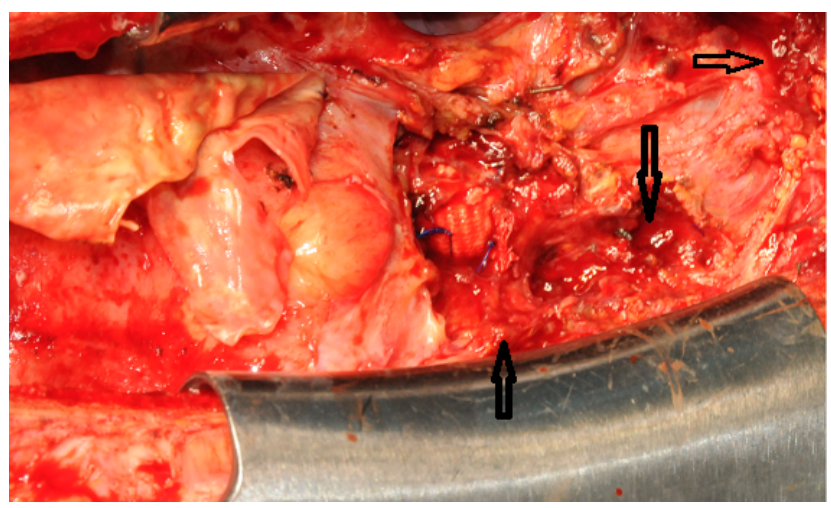

Figure 4:

completely intact. Under the PTFE membrane, the vast serous collection was seen (Figure 4). The granulation tissue was sampled for the microbiological tests. PTFE membrane was removed. There was not any microorganism in the sampled tissue and on the PTFE membrane. After the removal of PTFE patch, his sternum and skin healing were fast and well. He was discharged smoothly and on his firstyear control, there was no problem related to surgery.

\section{Discussions}

Reoperations for congenital cardiac defects relate to an increased surgical risk due to adhesions ${ }^{2,3}$. To avoid the adhesions, closing the pericardium is an efficient technique. Surgeons are trying to develop the pericardial closure method by using varied materials ${ }^{4-6}$.

Many techniques in cardiac surgery are being applied successfully by courtesy of PTFE patches ${ }^{7,8}$. One of them is closing the pericardium which is a useful technique against the sternal adhesions ${ }^{1}$. The nonbiologic materials such as PTFE patch may cause undesirable results. In this patient, 
sternal discharge occurred due to inflammatory reaction related to PTFE patch. However, the effectiveness of PTFE patch against the sternal adhesions is proved by many studies $^{1-9}$. On this basis, PTFE membranes should be used for patients who will need repeat operations, even though it has possible complications.

\section{Conclusion}

The prosthetic materials are being used in many kinds of surgeries ${ }^{10-12}$. These materials such as grafts, membranes, and patches are indispensable components of cardiovascular surgery. Various complications might be seen in these procedures due to prosthetic materials ${ }^{13}$. Cardiovascular complications are more complex and difficult to treat than other surgical complications ${ }^{14,15}$. Using the prosthetic materials for the benefits of patients might be complicated in rare times. If it is appropriate, the native pericardium rather than the prosthetic materials should be selected for pericardial closure.

To forget sponge - in the mediastinum or other anatomic chambers - in cardiac surgery is a rare but significant complication ${ }^{16}$. CT is one of the helpful technique for cardiac surgeons to plan the surgical procedures, but it should be kept in mind that CT imaging could be a misleading indicator unexpectedly.

\section{References}

1. Jukka T, Salminen Ilkka $\mathrm{P}$, Mattila Juha $\mathrm{T}$ et al. Prevention of postoperative pericardial adhesions in children with hypoplastic left heart syndrome Sairanen Interactive CardioVascular and Thoracic Surgery. Published by European Association for Cardio-Thoracic Surgery. 2011; 12: 270-272.

2. Russell JL, LeBlanc JG, Suvro SS, et al. Risks of repeat sternotomy in pediatric cardiac operations. Ann Thorac Surg. 1998; 66: 1575-1578.

3. Follis FM, Pett SB Jr, Miller KB, et al. Catastrophic hemorrhage on sternal reentry still a dreaded complication. Ann Thorac Surg. 1999; 68: 2215-2219.
4. Kaushal S, Patel SK, Goh SK, et al. A novel combination of bioresorbable polymeric film and expanded polytetrafluoroethylene provides a protective barrier and reduces adhesions. J Thorac Cardiovasc Surg. 2011 Mar; 1413: 789-95. doi: 10.1016/j.jtcvs.2010.11.043.

5. Bel A, Kachatryan L, Bruneval P, et al. A new absorbable collagen membrane to reduce adhesions in cardiac surgery. Interact Cardiovasc Thorac Surg. 2010 Feb; 102: 213-6. doi 10 1510/icvts 2009.215251 Epub 2009 Nov 2.

6. Daroz LR, Lopes JB, Dallan LA, et al. Prevention of postoperative pericardial adhesions using thermal sterile carboxymethyl chitosan. Rev Bras Cir Cardiovasc. 2008 Oct-Dec; 234: 480-7.

7. Maekawa Y, Sakamoto T, Umezu K, et al. Pulmonary valve replacement due to ectopic ossification on expanded polytetrafluoroethylene cusp after tetralogy of Fallot repair report of a case. Kyobu Geka. 2011 Mar; 643: 249-53.

8. Mohite PN, Sabashnikov A, Popov AF, et al. Use of PTFE patch for pericardial closure after minimal invasive LVAD implantation. Perfusion. 2015 Oct 30; pii0267659115615209.

9. Loebe M, Alexi Meskhishvili V, Weng $\mathrm{Y}$, et al. Use of polytetrafluoroethylene surgical membrane as a pericardial substitute in the correction of congenital heart defects. Tex Heart Inst J. 1993; 203: 213-7.

10. Xu Z, Min W, Zheyuan Y, et al. The treatment of upper eyelid sulcus using the expanded polytetrafluoroethylene implanted in orbit. 2015 Jul; 314: 284-7.

11. Cormier JM, Cormier F, Laurian C, et al. Polytetrafluoroethylene bypass for revascularization of the atherosclerotic internal carotid artery late results. Ann Vasc Surg. 1987 Dec; 15: 564-71.

12. Eishi K, Kawazoe K, Nakano K, et al. Long term results of artificial chordae implantation in patients with mitral valve prolapse. J Heart Valve Dis. 1997 Nov; 66: 594-8.

13. Salamone G, Licari L, Agrusa A, et al. Deep seroma after incisional hernia repair Case reports and review of the literature. Ann Ital Chir. 2015 May 12; 86: ePub pii S2239253X15022938.

14. Bachleda P, Utikal P, Kalinova L, et al. Infectious complications of arteriovenous ePTFE grafts for hemodialysis. Biomed Pap Med Fac Univ Palacky Olomouc Czech Repub. 2010 Mar; 1541: 13-9.

15. Chalmers RT, Wolfe JH, Cheshire NJ, et al. Improved management of infra inguinal bypass graft infection with methicillin resistant Staphylococcus aureus. A different intracardiac mass retained sponge Echocardiography. 2006 Apr; 234: 322-3. 